\title{
ARTICLE
}

Clinical Research

\section{Cardiac biomarkers in patients with prostate cancer and cardiovascular disease receiving gonadotrophin releasing hormone agonist vs antagonist}

\author{
David Margel ${ }^{1,2} \cdot$ Yaara Ber $^{1} \cdot$ Avivit Peer $^{3,4} \cdot$ Liat Shavit-Grievink $^{1,5} \cdot$ Jehonathan H. Pinthus $^{6} \cdot$ Guy Witberg $^{7}$. \\ Jack Baniel ${ }^{1,2} \cdot$ Daniel Kedar $^{1} \cdot$ Eli Rosenbaum ${ }^{5}$
}

Received: 12 May 2020 / Revised: 12 July 2020 / Accepted: 24 July 2020 / Published online: 31 July 2020

(c) The Author(s), under exclusive licence to Springer Nature Limited 2020

\begin{abstract}
Background Gonadotrophin releasing hormone $(\mathrm{GnRH})$ agonists and antagonists reduce testosterone levels for the treatment of advanced and metastatic prostate cancer. Androgen deprivation therapy (ADT) is associated with increased risk of cardiovascular (CV) events and CV disease (CVD), especially in patients with preexisting CVD treated with GnRH agonists. Here, we investigated the potential relationship between serum levels of the cardiac biomarkers $\mathrm{N}$-terminal pro-B-type natriuretic peptide (NTproBNP), D-dimer, C-reactive protein (CRP), and high-sensitivity troponin (hsTn) and the risk of new $\mathrm{CV}$ events in prostate cancer patients with a history of CVD receiving a GnRH agonist or antagonist.

Methods Post-hoc analyses were performed of a phase II randomized study that prospectively assessed CV events in patients with prostate cancer and preexisting CVD, receiving GnRH agonist or antagonist. Cox proportional hazards models were used to determine whether the selected biomarkers had any predictive effect on CV events at baseline and across a 12month treatment period.

Results Baseline and disease characteristics of the 80 patients who took part in the study were well balanced between treatment arms. Ischemic heart disease (66\%) and myocardial infarction (37\%) were the most common prior CVD and the majority (92\%) of patients received CV medication. We found that high levels of NTproBNP ( $p=0.008)$, and hsTn $(p=$ 0.004) at baseline were associated with the development of new CV events in the GnRH agonist group but not in the antagonist. In addition, a nonsignificant trend was observed between higher levels of NTproBNP over time and the development of new CV events in the GnRH agonist group.

Conclusions The use of cardiac biomarkers may be worthy of further study as tools in the prediction of CV risk in prostate cancer patients receiving ADT. Analysis was limited by the small sample size; larger studies are required to validate biomarker use to predict $\mathrm{CV}$ events among patients receiving ADT.
\end{abstract}

David Margel

sdmargel@gmail.com

Division of Urology, Rabin Medical Center, Petach Tikva, Israel

2 Sackler Faculty of Medicine, Tel Aviv University, Tel Aviv, Israel

3 Department of Oncology, Rambam Health Care Campus, Haifa, Israel

4 Rappaport Faculty of Medicine, Technion, Haifa, Israel

5 Davidoff Cancer Centre, Rabin Medical Center, Petach Tikva, Israel

6 Department of Surgery, Division of Urology, McMaster University, Hamilton, ON, Canada

7 Department of Cardiology, Rabin Medical Center, Petach Tikva, Israel

\section{Introduction}

Androgen deprivation therapy (ADT) is the mainstay treatment for locally advanced and metastatic prostate cancer [1]. Pharmaceutical ADTs include gonadotrophin releasing hormone $(\mathrm{GnRH})$ agonists and $\mathrm{GnRH}$ antagonists that inhibit luteinizing hormone secretion and subsequently reduce testosterone production by different mechanisms $[1,2]$. ADT has been associated with cardiovascular (CV) mortality [3], which now precedes cancer as the most common cause of death in men with prostate cancer [4].

Observational studies have shown that GnRH agonists are associated with increased risk of CV morbidity and mortality, whereas the risk maybe lower with GnRH antagonists [5-8]. Further, patients with CV comorbidities 
are at higher risk than those without $[3,9,10]$. For example, a meta-analysis of data pooled from six phase III trials showed significantly increased risk of $\mathrm{CV}$ disease (CVD) and $\mathrm{CV}$ mortality in patients receiving GnRH agonists compared with $\mathrm{GnRH}$ antagonist [3]. The reduction in $\mathrm{CV}$ events associated with GnRH antagonist compared with agonist was in patients with preexisting CVD. However, $\mathrm{CV}$ outcomes were assessed as safety events and were not a prespecified endpoint.

We recently reported findings from the first randomized phase II study that prospectively assessed CV outcomes in men with advanced prostate cancer and preexisting CVD [11]. In this study, the GnRH antagonist, degarelix, was associated with an $18 \%$ reduction in the risk of CV events compared with a GnRH agonist over 1 year in patients with CVD comorbidities. In the HERO trial [12], which enrolled 934 men, the incidence of major adverse CV events after 48 weeks of treatment was $2.9 \%$ with relugolix (oral GnRH antagonist) and $6.2 \%$ with leuprolide (GnRH agonist). In the subgroup of men with a history of CV events, the incidence was $3.6 \%$ in the relugolix group and $17.8 \%$ in the leuprolide group, indicating that the risk differed by a factor of 4.8. In both studies, CV events were secondary outcomes. Current evidence therefore suggests that GnRH antagonists may be preferable to GnRH agonists for patients with preexisting CVD.

ADT treatment is often effective over a sustained period of time and so methods of identifying patients at high risk of CVD and CV mortality are required [1, 13]. N-terminal proB-type natriuretic peptide (NTproBNP), D-dimer, Creactive protein (CRP), and high-sensitivity troponin (hsTn) are known cardiac biomarkers [14]. Previously we showed that higher serum NTproBNP levels at baseline were significantly associated with increased risk of a CV event within 1 year of ADT in patients with preexisting CVD [11]. Here, we report the findings of exploratory posthoc analyses that assessed the effect of serum levels of NTproBNP, D-dimer, CRP and hsTn on the risk of new CV events for patients with prostate cancer and preexisting CVD, treated with GnRH agonist vs antagonist.

\section{Methods}

\section{Trial design and data collection}

A bi-center, phase II, randomized, open-label superiority study was conducted, in which men with high-risk or metastatic prostate cancer and a documented history of CVD (myocardial infarction [MI], cerebrovascular accident [CVA], ischemic heart disease [IHD], or peripheral vascular disease) received GnRH agonist or antagonist. Patients scheduled to receive ADT for at least 1 year, who had not received ADT within the last 6 months, were eligible. The primary outcome compared endothelial function and was described previously [11].

$\mathrm{CV}$ events were a predefined secondary outcome and included MI, CVA, transient ischemic attack, heart catheterization with/without intervention, cardiac-related hospitalization, and death. Further, major adverse $\mathrm{CV}$ and cerebrovascular events (MACCE) were defined as MI, CVA, heart catheterization with stent insertion, and death. A cardiologist blinded to treatment assignment reviewed patient medical records every 3 months to identify new CV and MACCE events.

The serum levels of cardiac markers NTproBNP, Ddimer, CRP, and hsTn were measured at baseline and after 3,6 , and 12 months of treatment. NTproBNP and hsTn (type $\mathrm{T}$ ) were measured using a Roche cobas e411 analyzer, CRP was measured using a Roche cobas 8000 modular analyzer (c701 module), and D-dimer was measured using a Werfen ACL TOP automatic coagulation analyzer by standard protocol.

\section{Statistical analysis}

Post-hoc analyses were performed to test whether there was an interaction between ADT modality, cardiac biomarkers, and CVD risk. A Cox proportional hazards model was fitted to the time to $\mathrm{CV}$ event to assess evidence of a treatment effect across different biomarker values. This included terms for treatment arm, log transformed baseline biomarker level, and biomarker-by-treatment interaction.

In addition, patients were grouped dependent on their baseline levels of the selected biomarkers to investigate if there was any relationship between high/low levels at baseline and $\mathrm{CV}$ risk in each treatment arm. We used twosided Fisher's exact test for this analysis. NTproBNP, Ddimer, and CRP were analyzed by tertiles. hsTn could not be analyzed by tertiles as more than half of the subjects had hsTn below detection levels $(<14 \mathrm{ng} / \mathrm{L})$. All biomarkers were analyzed using current clinical cutoff levels that suggest increased risk for heart failure; $500 \mathrm{ng} / \mathrm{ml}$ for D-dimer, $14 \mathrm{ng} / \mathrm{L}$ for hsTn. For CRP we used $0.1 \mathrm{mg} / \mathrm{dL}$ as lower cutoff and $0.3 \mathrm{mg} / \mathrm{dL}$ as higher cutoff. For NTproBNP we used $400 \mathrm{pg} / \mathrm{mL}$ as higher threshold. A lower NTproBNP threshold of $125 \mathrm{pg} / \mathrm{mL}$ was also analyzed as a recent study suggests that it has higher sensitivity than the current cutoff of $400 \mathrm{pg} / \mathrm{mL}$, which is recommended by the National Institute for Health and Care Excellence (NICE) [15].

An analysis was also undertaken to determine if there was any relationship between serum cardiac biomarker levels and the risk of new CV events across the 12-month treatment period. This model fitted $\log$ transformed biomarker values, including terms for treatment arm, log transformed baseline biomarker level, time, and treatment- 
Table 1 Patient characteristics at baseline related to cardiovascular health.

\begin{tabular}{|c|c|c|}
\hline & $\begin{array}{l}\text { GnRH agonist } \\
(N=39)\end{array}$ & $\begin{array}{l}\text { Degarelix } \\
(N=41)\end{array}$ \\
\hline Age, median (IQR) & $71(69-78)$ & $72(66-77)$ \\
\hline BMI, median (IQR) & $27.4(25.1-29.1)$ & $28(25-29.9)$ \\
\hline \multicolumn{3}{|l|}{ CVD history } \\
\hline $\begin{array}{l}\text { Myocardial infarction } \\
\text { within } 1 \text { year prior to } \\
\text { randomization }\end{array}$ & $15(38)$ & $15(37)$ \\
\hline $\begin{array}{l}\text { Cerebrovascular } \\
\text { condition }\end{array}$ & $8(21)$ & $6(15)$ \\
\hline Ischemic heart disease & $26(67)$ & $27(66)$ \\
\hline $\begin{array}{l}\text { Peripheral vascular } \\
\text { disease }\end{array}$ & $2(5)$ & $4(10)$ \\
\hline \multicolumn{3}{|l|}{ Comorbidities } \\
\hline Hypertension & $29(74)$ & $29(71)$ \\
\hline Diabetes & $15(38)$ & $10(24)$ \\
\hline Renal failure & $1(3)$ & $3(7)$ \\
\hline \multicolumn{3}{|l|}{ Smoking } \\
\hline Never & $17(44)$ & $17(41)$ \\
\hline Past & $16(41)$ & $18(44)$ \\
\hline Current & $5(13)$ & $4(10)$ \\
\hline Unknown & $1(3)$ & $2(5)$ \\
\hline \multicolumn{3}{|l|}{ CVD prevention drugs } \\
\hline Statins & $29(74)$ & $29(71)$ \\
\hline Antiplatelets & $31(79)$ & $26(63)$ \\
\hline Beta-blocker & $18(46)$ & $15(37)$ \\
\hline $\mathrm{ACEi}$ & $15(38)$ & $21(51)$ \\
\hline
\end{tabular}

Values are $n(\%)$ unless otherwise stated.

$A C E i$ angiotensin converting enzyme inhibitor, $B M I$ body mass index, $C V D$ cardiovascular disease, $G n R H$ gonadotrophin releasing hormone, $I Q R$ interquartile range.

by-time interaction. All analyses were performed using PROC PHREG in SAS (Version 9.4) and SPSS ver 21.

\section{Results}

\section{Patient characteristics}

A total of 80 patients were enrolled in the study, 39 of whom received GnRH agonist, and $41 \mathrm{GnRH}$ antagonist. The overall baseline and disease characteristics were well balanced between treatment arms (Table 1). IHD and MI were the most common prior CVD; 53 (66\%) patients had a history of IHD, $30(37 \%)$ patients an MI within 1 year prior to randomization, and $74(92.5 \%)$ patients received treatment for secondary $\mathrm{CV}$ prevention. The median BMI was 27.4 (IQR 25.1-29.1) for the GnRH agonist group and 28 (IQR 25-29.9) for the antagonist group. A total of
25 patients $(31 \%)$ had diabetes, 58 patients $(73 \%)$ had hypertension, and $55(69 \%)$ received at least 4 types of medication. Baseline risk factors such as hypertension, diabetes, BMI, and smoking were balanced with no statistically significant difference between the arms.

\section{Baseline levels of cardiac biomarkers and CV events by treatment arm}

The baseline levels of NTproBNP, D-dimer, CRP, and hsTn for each patient were stratified by study arm and the development of new CV and MACCE events in order to determine any predictive treatment effect on $\mathrm{CV}$ outcome (Fig. 1). A total of 15 new CV events occurred during the study; 13 in the GnRH agonist arm, and 2 in the degarelix arm ( $p$ value $=$ 0.001). Analysis of NTproBNP and hsTn identified a potential trend between higher levels at baseline and a CV or MACCE event (Fig. 1a, c). No relationship between baseline CRP and D-dimer levels and CV or MACCE events within 12 months of GnRH agonist or antagonist treatment were observed (Fig. 1b, d). No significant treatment-by-biomarker interactions were found, although statistical comparisons were limited by the small number of patients in the antagonist arm who developed a CV or MACCE event.

To further characterize any association between baseline biomarker levels and CV events in each treatment arm, patients were grouped by both tertiles and current clinical values (Table 2). We found that high levels of NTproBNP at baseline were associated with the development of new CV events in the GnRH agonist group but not in the antagonist (Fig. 2). This was true both for the tertiles analysis (Fig. 2a) and clinical values (Fig. 2b), in a dose response manner. In a similar analysis we also found that high levels of hsTn were associated with a new CV event in the GnRH agonist arm but not in the antagonist arm (Fig. 2g). High levels of D-dimer (Fig. 2b, c) and CRP (Fig. 2e, f) were not found to be significant.

\section{Levels of cardiac biomarkers over time}

The levels of NTproBNP, D-dimer, CRP, and hsTn were analyzed across the 12-month treatment period to investigate treatment-by-time interactions (Fig. 3). To this end, the log transformed biomarker values for each patient at baseline, 3, 6, and 12 months were stratified by study arm and CV event. The values of NTproBNP, D-dimer, CRP, and hsTn did not show any noteworthy change in distribution between patients who experienced a new CV event and those who did not over 12 months. Despite a large amount of overlap in the NTproBNP serum levels of patients who did and did not experience a $\mathrm{CV}$ event, there was some indication that patients who experienced $\mathrm{CV}$ events had slightly higher NTproBNP levels than those who did not. 

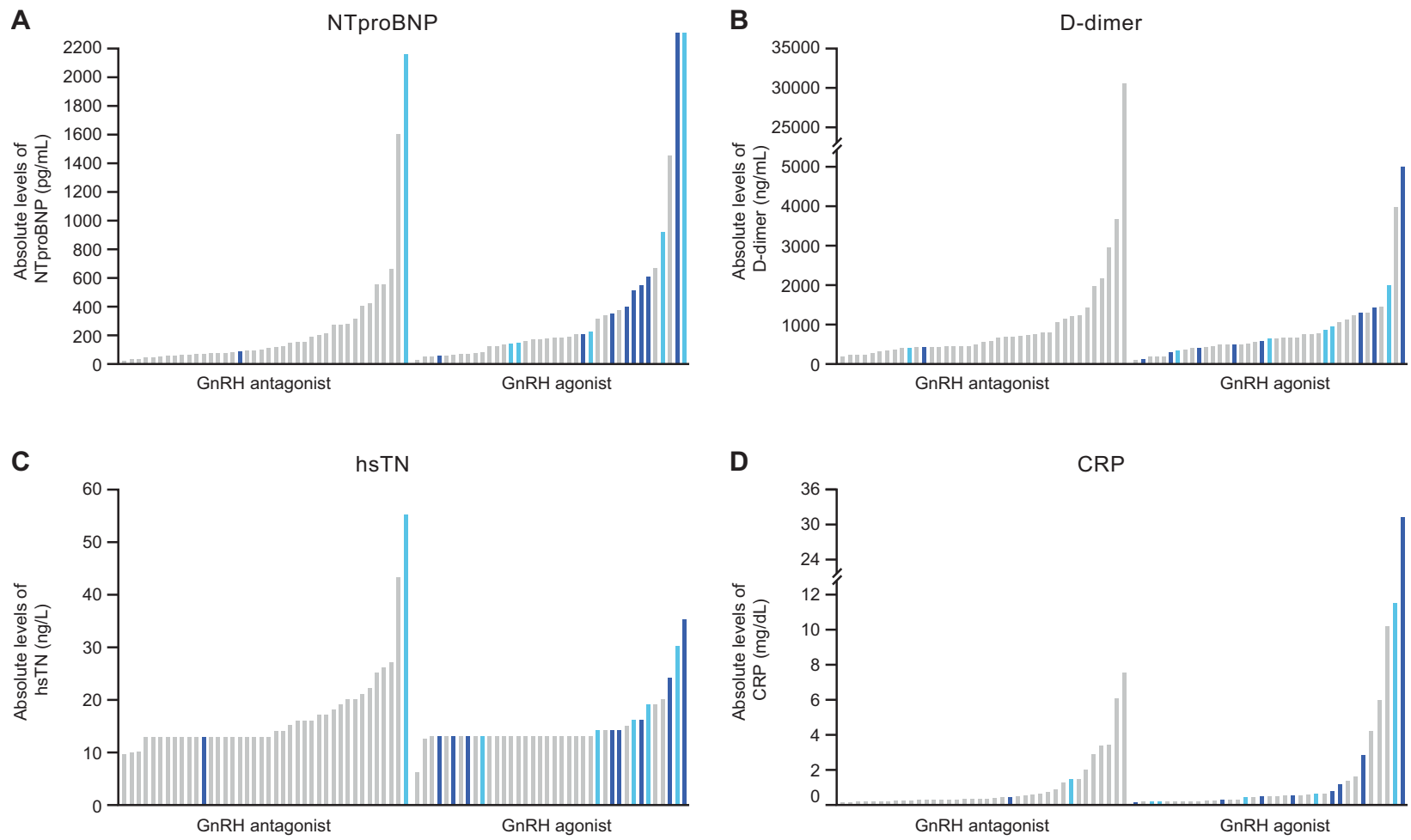

hsTN
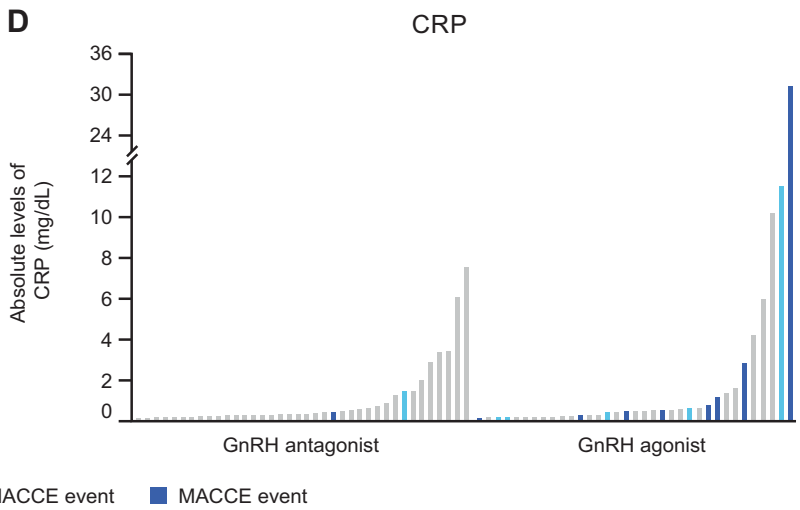

Fig. 1 Baseline levels of CV biomarkers NTproBNP, D-Dimer, hsTn, and CRP for each patient stratified by study arm and CV event. CRP C-reactive protein; CV cardiovascular; GnRH gonadotrophin releasing hormone; hsTn high-sensitivity troponin; MACCE major adverse cardiac and cerebrovascular event; NTproBNP Nterminal pro-B-type natriuretic peptide. Cardiovascular related events

(CVE) included death, myocardial infarction, cerebrovascular accident, transient ischemic attack, heart catheterization with or without intervention, and cardiac-related hospitalization, and MACCEs included death, myocardial infarction, cerebrovascular accident, and heart catheterization with stent. Non-MACCE events are CVEs that are not MACCE.

\section{Discussion}

Here, we present exploratory post-hoc analyses of the first phase II clinical trial that prospectively assessed CV outcomes for men with prostate cancer and preexisting CVD. We tested whether the serum levels of cardiac biomarkers NTproBNP, D-dimer, CRP, and hsTn at baseline and during 12 months of treatment with GnRH agonist or antagonist had any association with $\mathrm{CV}$ risk. We found that high levels of NTproBNP and hsTn at baseline were associated with the development of new $\mathrm{CV}$ events in the GnRH agonist group but not in the antagonist. In addition, we presented preliminary evidence that patients with higher levels of NTproBNP at baseline and across a 12-month treatment period with $\mathrm{GnRH}$ agonist were more likely to develop a $\mathrm{CV}$ event.

NTproBNP in an inactive prohormone that is released in response to increased pressure within the heart and has a major role in the screening and diagnosis of cardiac disease [16-18]. Elevated NTproBNP levels are associated with a high risk of pulmonary edema, acute MI, and CV morbidity and mortality $[16,17,19-23]$. NTproBNP values independently predict postoperative cardiac events following

noncardiac major vascular surgery and the clinical outcome of patients with heart failure [19, 24-28]. Clinical evaluation of NTproBNP in the blood is a standard, relatively simple test that avoids the costs and time required for cardiac diagnostic testing [26].

The findings presented here suggest that serum NTproBNP levels could also be a predictive biomarker for $\mathrm{CV}$ risk in patients with prostate cancer and preexisting CVD who receive GnRH agonists. Such patients with high NTproBNP levels may benefit from GnRH antagonists such as antagonist. However, only a small number of patients in the antagonist arm developed a CV event and this compounded statistical comparisons between the treatment arms.

Analysis of baseline NTproBNP levels, in the GnRH agonist arm, found that $8 \%$ (1 of 12) of patients with NTproBNP $<125 \mathrm{pg} / \mathrm{mL}, 33 \%$ (6 of 18) of patients with NTproBNP between 125 and $400 \mathrm{~g} / \mathrm{mL}$, and $75 \%$ (6 of 8 ) of patients with NTproBNP levels $>400 \mathrm{pg} / \mathrm{mL}$, developed $\mathrm{CV}$ events. Current recommendations by NICE state that patients suspected of heart failure with NTproBNP levels of higher than $400 \mathrm{pg} / \mathrm{mL}$ should be referred to a specialist within 6 weeks, although a recent review of these guidelines 
Table 2 Percentage of patients who had a CV event stratified by study arm and their baseline levels of NTproBNP, D-dimer, CRP, and hsTn.

\begin{tabular}{|c|c|c|c|c|}
\hline & Biomarker level & $\begin{array}{l}\text { GnRH agonist events/ } \\
\text { patients }(\%)\end{array}$ & $\begin{array}{l}\text { GnRH antagonist } \\
\text { events/patients }(\%)\end{array}$ & $p$ value \\
\hline \multicolumn{5}{|l|}{ Tertiles } \\
\hline \multirow[t]{3}{*}{ NTproBNP, pg/mL } & $\mathrm{NT} \leq 72$ & $1 / 10(10)$ & $0 / 16(0)$ & 0.38 \\
\hline & $72<\mathrm{NT}<202$ & $3 / 14(21)$ & $1 / 12(8)$ & 0.6 \\
\hline & $\mathrm{NT} \geq 202$ & $9 / 14(64)$ & $1 / 12(8)$ & 0.0053 \\
\hline$p$ value & & 0.011 & 0.51 & \\
\hline \multirow[t]{3}{*}{ D-dimer, $\mathrm{ng} / \mathrm{mL}$} & D-dimer $\leq 443$ & $4 / 12(33)$ & $2 / 14(14)$ & 0.37 \\
\hline & $443<$ D-dimer $<760$ & $3 / 13$ & $0 / 13(0)$ & 0.22 \\
\hline & D-dimer $\geq 760$ & $6 / 14(43)$ & $0 / 14(0)$ & 0.016 \\
\hline$p$ value & & 0.58 & 0.32 & \\
\hline \multirow[t]{3}{*}{$\mathrm{CRP}, \mathrm{mg} / \mathrm{dL}$} & $\mathrm{CRP} \leq 0.18$ & $4 / 13(31)$ & $0 / 12(0)$ & 0.1 \\
\hline & $0.18<\mathrm{CRP}<0.48$ & $3 / 10(30)$ & $1 / 15(7)$ & 0.27 \\
\hline & $\mathrm{CRP} \geq 0.48$ & $6 / 13(46)$ & $1 / 13(8)$ & 0.07 \\
\hline$p$ value & & 1.0 & 1.0 & \\
\hline \multicolumn{5}{|l|}{ Clinical values } \\
\hline \multirow[t]{3}{*}{ NTproBNP, pg/mL } & $\mathrm{NT} \leq 125$ & $1 / 12(8)$ & $1 / 23(4)$ & 0.99 \\
\hline & $125<\mathrm{NT}<400$ & $6 / 18(33)$ & $0 / 10(0)$ & 0.06 \\
\hline & $\mathrm{NT} \geq 400$ & $6 / 8(75)$ & $1 / 7(14)$ & 0.04 \\
\hline$p$ value & & 0.008 & 0.38 & \\
\hline \multirow[t]{2}{*}{ D-dimer, $\mathrm{ng} / \mathrm{mL}$} & D-dimer $<500$ & $5 / 15$ & 2/19 (12) & 0.2 \\
\hline & D-dimer $\geq 500$ & $8 / 24(33)$ & $0 / 22(0)$ & 0.004 \\
\hline$p$ value & & 1 & 0.21 & \\
\hline \multirow[t]{3}{*}{ CRP, mg/dL } & $\mathrm{CRP}<0.1$ & $3 / 7(43)$ & $0 / 5(0)$ & 0.2 \\
\hline & $0.1 \leq \mathrm{CRP} \leq 0.3$ & $1 / 8(13)$ & $0 / 18(0)$ & 0.32 \\
\hline & $\mathrm{CRP}>0.3$ & $9 / 23(39)$ & 2/17 (12) & 0.07 \\
\hline$p$ value & & 0.32 & 0.41 & \\
\hline \multirow[t]{2}{*}{ hsTn, ng/L } & hsTn $<14$ & $4 / 25$ & $1 / 21(5)$ & 0.36 \\
\hline & hsTn $\geq 14$ & $9 / 14(64)$ & $1 / 19(5)$ & 0.0004 \\
\hline$p$ value & & 0.004 & 1.0 & \\
\hline
\end{tabular}

Data not available for one patient in each arm for NTproBNP, three patients in the GnRH agonist arm and one in the GnRH antagonist arm for CRP, and one patient in the GnRH antagonist arm for hsTn. $p$ value was calculated using Fisher's exact test.

$C R P$ C-reactive protein, $C V$ cardiovascular, $G n R H$ gonadotrophin releasing hormone, $h s T n$ high-sensitivity troponin, $N T$ proBNP $\mathrm{N}$-terminal pro-B-type natriuretic peptide. suggests that this cutoff should be as low as $125 \mathrm{pg} / \mathrm{mL}$ [15]. The lower threshold of $125 \mathrm{pg} / \mathrm{mL}$ may therefore be relevant to distinguish patients receiving $\mathrm{GnRH}$ agonist at risk of secondary cardiac events.

In addition to NTproBNP, we also saw that high levels of baseline hsTn were associated with an increased risk for CV event in the GnRH agonist group. Troponin is considered the gold standard for identifying myocardial injury due to its sensitivity, and high cardiac specificity [29]. It is released from dead heart cells into the blood stream, indicating cardiac injury. The development of hsTn assays in the last decade enabled identification of even small amounts of cardiac damage. hsTn is mostly used for diagnoses of MI, but also for other cardiac-related conditions such as obstructive coronary artery disease, Stable angina,
Congestive heart failure, and cardiomyopathy [30]. Serum levels of $14 \mathrm{ng} / \mathrm{L}$ are considered the clinical cutoff and were used in our analyses [31]. We found that $64 \%$ of patients in the GnRH agonist arm who had high baseline levels of hsTn suffered a CV event within 12 months of initiating ADT. We did not observe a change in hsTn overtime.

Evidence suggesting a differential ADT class effect between GnRH agonist and antagonist on cardiac outcomes is now accumulating [3, 11, 12]. Previous studies have shown that low testosterone levels are associated with an increased CV risk. However, both classes of drugs (agonist and antagonists) induce castrate levels of testosterone [32]. An alternative explanation could be FSH. GnRH antagonists effectively suppress FSH, while GnRH agonists gradual decrease it to about 50\% [32]. FSH receptors are found 
Tertiles
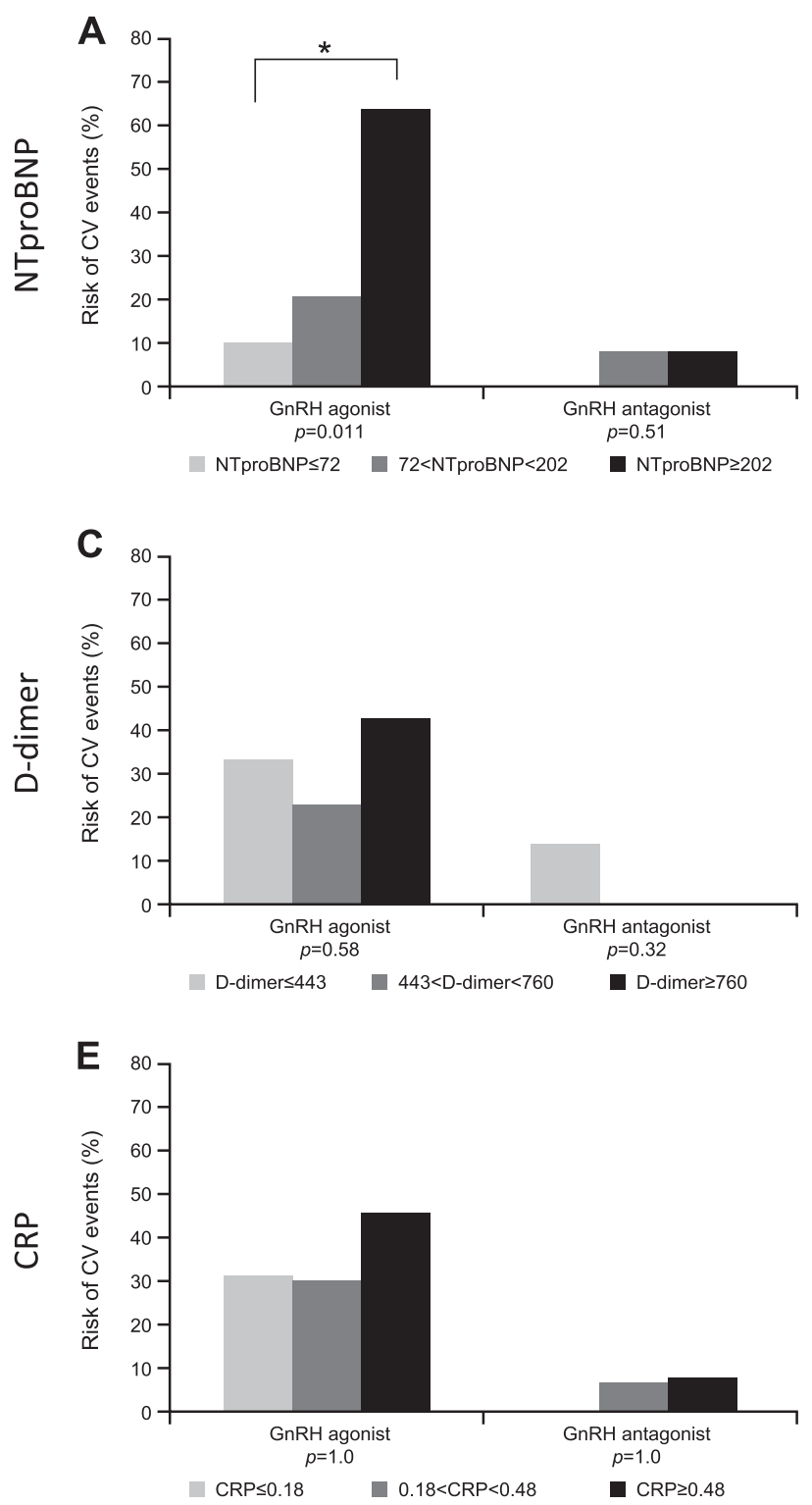

Fig. 2 Risk for $\mathrm{CV}$ in GnRH agonist vs antagonist, based on baseline levels of cardiac biomarkers grouped by tertiles and current clinical values. CRP C-reactive protein; CV cardiovascular;
Clinical values
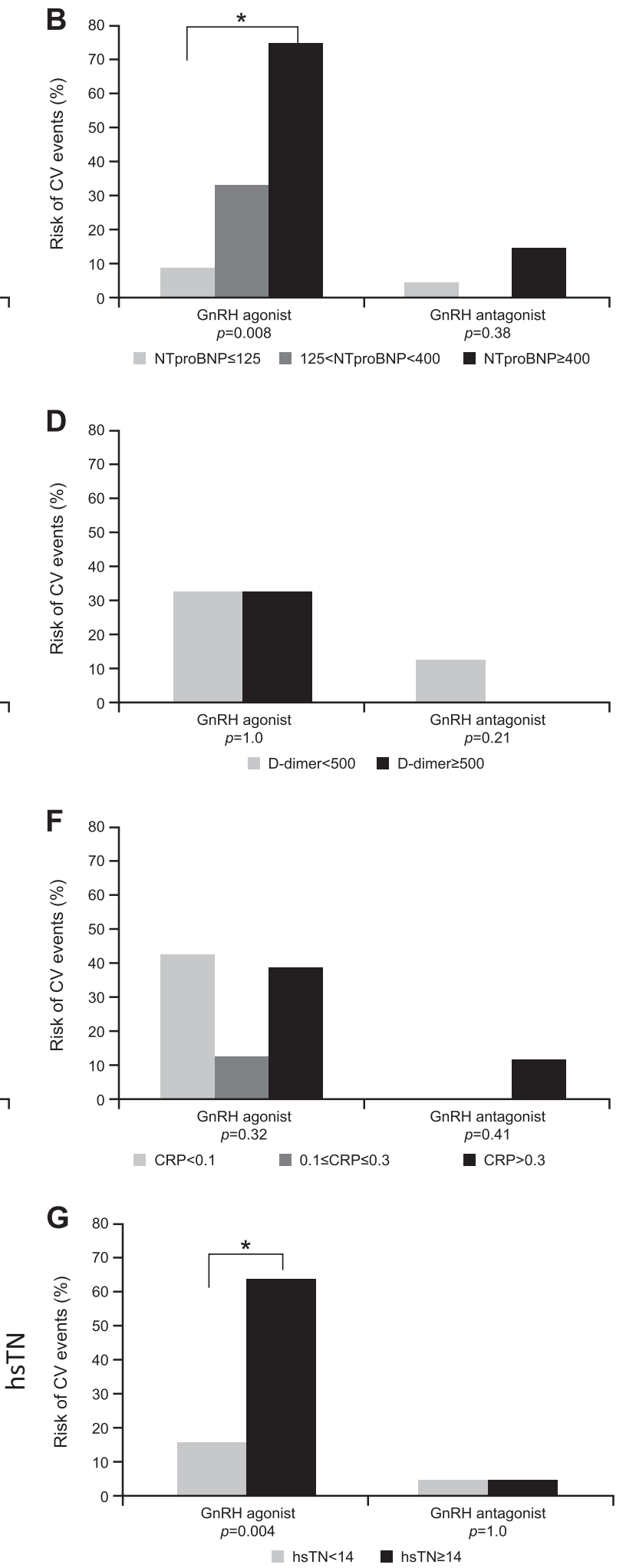

hsTn high-sensitivity troponin; NTproBNP N-terminal pro-B-type natriuretic peptide. ${ }^{*} p$ value $<0.05$; exact $p$ values are detailed under each graph. $p$ value was calculated using two-sided Fisher's exact test. 
A

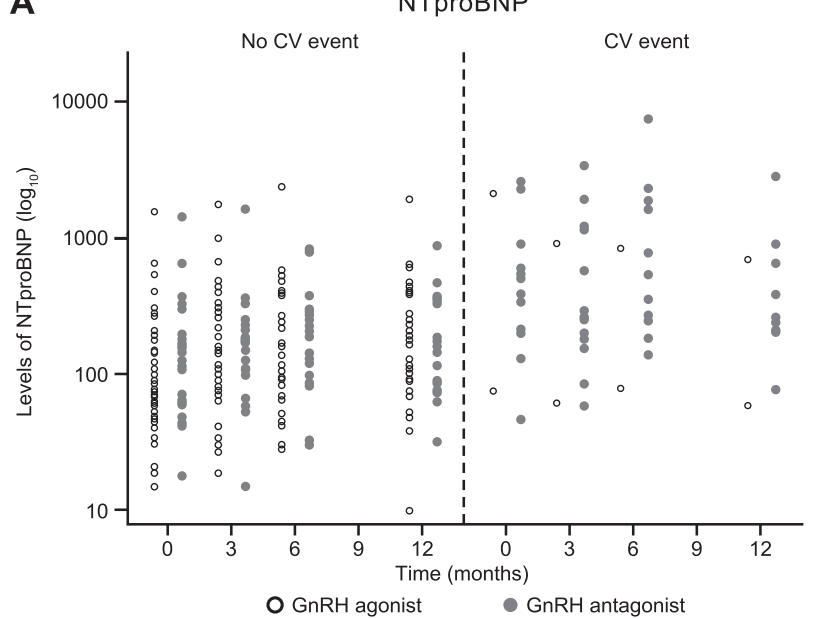

C

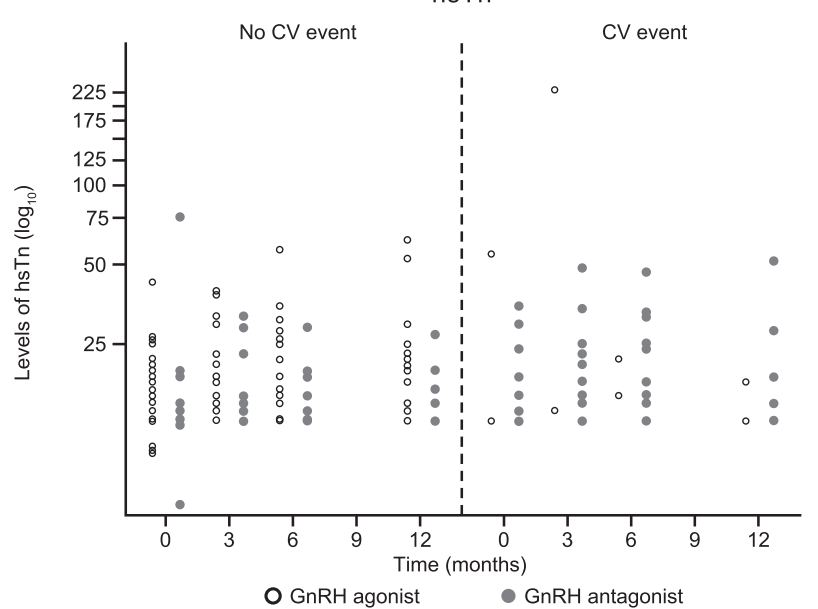

B

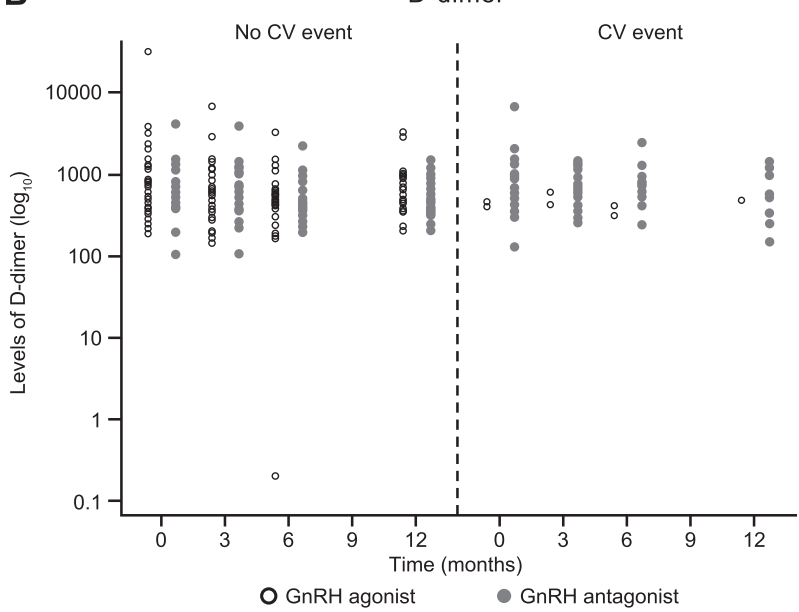

D

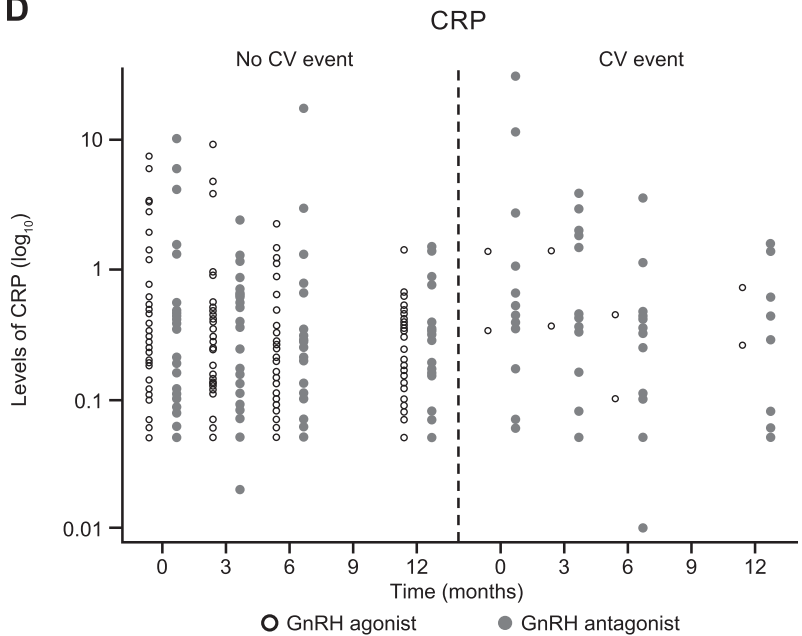

Fig. 3 Levels of biomarkers over time stratified by treatment arm and CV event. CRP C-reactive protein; CV cardiovascular; hsTn highsensitivity troponin; NTproBNP N-terminal pro-B-type natriuretic peptide.

on the luminal endothelial surface of proliferating tissue and may play a role in endothelial cell function, lipid metabolism, and fat accumulation that may increase the risk of CVD in men receiving GnRH agonist [33]. Another possibility is a direct effect on the GnRH receptor itself. GnRH agonists (but not antagonists) bind to GnRH receptors on $\mathrm{T}$ cells, thus stimulates a pro-inflammatory phenotype, which may contribute to destabilization of atherosclerotic plaques [34]. Although these mechanistic differences are out of the scope of our study, we provide preliminary data to suggest that a simple blood test may identify men at risk.

The identification of patients with prostate cancer and preexisting CVD at risk of secondary $\mathrm{CV}$ events is of upmost importance. Data from the HERO study [12] suggest that among men with a history of $\mathrm{CV}$ events, the risk of a $\mathrm{CV}$ event during ADT is high. Our findings have highlighted a potential role for NTproBNP and hsTn in the clinical risk evaluation of ADT modality; serum NTproBNP and/or hsTn levels could be a useful and simple tool for urologists when deciding on ADT treatment for patients with a preexisting CVD. If validated, these biomarkers maybe used to triage before commencing ADT. This warrants further investigation in the ongoing, larger phase III trial that will prospectively assess $\mathrm{CV}$ risk in patients with prostate cancer and CVD receiving $\mathrm{GnRH}$ agonist or $\mathrm{GnRH}$ antagonist degarelix (NCT02663908).

Acknowledgements This work was supported as an Investigator Initiated Trial by Ferring Pharmaceuticals (received by DM). The company had no role in the design and conduct of the study; collection, management, analysis, and interpretation of the data; preparation, review, or approval of the paper; and decision to submit the paper for publication. Medical writing support was provided by Sam Lommano, Bioscript Science, and support with statistical analyses was provided by Aaron Dane, DaneStat, supported by Ferring Pharmaceuticals.

Author contributions DM, YB, LSG, JHP, JB, and ER conceived and/ or designed the study. YB, AP, DK, and ER acquired the data, and 
DM, YB, and GW had an important role in interpreting the results. All authors were involved in drafting and revising the paper and approved the final version and take responsibility for the work.

\section{Compliance with ethical standards}

Conflict of interest DM and JHP have received honoraria and research grants from Ferring Pharmaceuticals. All other authors have no conflicts of interest to declare.

Publisher's note Springer Nature remains neutral with regard to jurisdictional claims in published maps and institutional affiliations.

\section{References}

1. Cornford P, Bellmunt J, Bolla M, Briers E, De Santis M, Gross T, et al. EAU-ESTRO-SIOG Guidelines on prostate cancer. Part II: treatment of relapsing, metastatic, and castration-resistant prostate cancer. Eur Urol. 2017;71:630-42.

2. Perlmutter MA, Lepor H. Androgen deprivation therapy in the treatment of advanced prostate cancer. Rev Urol. 2007;9 Suppl 1: S3-8.

3. Albertsen PC, Klotz L, Tombal B, Grady J, Olesen TK, Nilsson J. Cardiovascular morbidity associated with gonadotropin releasing hormone agonists and an antagonist. Eur Urol. 2014;65:565-73.

4. Mottet N, van den Vergh RCN, Briers E, Bourke L, Cornford P, de santis $\mathrm{M}$, et al. EAU-ESTRO-ESUR-Guidelines on prostate cancer European Association of Urology 2018. https:// uroweb.org/wp-content/uploads/EAU-ESUR-ESTRO-SIOG-

Guidelines-on-Prostate-Cancer-large-text-V2.pdf.

5. Bosco C, Bosnyak Z, Malmberg A, Adolfsson J, Keating NL, Van Hemelrijck M. Quantifying observational evidence for risk of fatal and nonfatal cardiovascular disease following androgen deprivation therapy for prostate cancer: a meta-analysis. Eur Urol. 2015;68:386-96.

6. Gandaglia G, Sun M, Popa I, Schiffmann J, Trudeau V, Shariat $\mathrm{SF}$, et al. Cardiovascular mortality in patients with metastatic prostate cancer exposed to androgen deprivation therapy: a population-based study. Clin Genitourin Cancer. 2015;13: e123-30.

7. O'Farrell S, Garmo H, Holmberg L, Adolfsson J, Stattin P, Van Hemelrijck M. Risk and timing of cardiovascular disease after androgen-deprivation therapy in men with prostate cancer. J Clin Oncol. 2015;33:1243-51.

8. Greiman AK, Keane TE. Approach to androgen deprivation in the prostate cancer patient with pre-existing cardiovascular disease. Curr Urol Rep. 2017;18:41.

9. Nanda A, Chen M-H, Braccioforte MH, Moran BJ, D'Amico AV. Hormonal therapy use for prostate cancer and mortality in men with coronary artery disease-induced congestive heart failure or myocardial infarction. JAMA. 2009;302:866-73.

10. D'Amico AV, Chen M-H, Renshaw AA, Loffredo M, Kantoff PW. Androgen suppression and radiation vs radiation alone for prostate cancer. A randomized trial. JAMA. 2008;299:289-95.

11. Margel D, Peer A, Ber Y, Shavit-Grievink L, Tabachnik T, Sela S, et al. Cardiovascular morbidity in a randomized trial comparing GnRH agonist and GnRH antagonist among patients with advanced prostate cancer and preexisting cardiovascular disease. J Urol. 2019;202:1199-208.

12. Shore ND, Saad F, Cookson MS, George DJ, Saltzstein DR, Tutrone R, et al. Oral relugolix for androgen-deprivation therapy in advanced prostate cancer. N Engl J Med. 2020;382:2187-96.
13. Horwitz EM, Bae K, Hanks GE, Porter A, Grignon DJ, Brereton $\mathrm{HD}$, et al. Ten-year follow-up of radiation therapy oncology group protocol 92-02: a phase III trial of the duration of elective androgen deprivation in locally advanced prostate cancer. J Clin Oncol. 2008;26:2497-504.

14. Hijazi Z, Oldgren J, Siegbahn A, Granger CB, Wallentin L. Biomarkers in atrial fibrillation: a clinical review. Eur Heart $\mathrm{J}$. 2013;34:1475-80

15. Taylor CJ, Roalfe AK, Iles R, Hobbs FR, Barton P, Deeks J, et al. Primary care REFerral for EchocaRdiogram (REFER) in heart failure: a diagnostic accuracy study. Br J Gen Pract. 2017;67: e94-102.

16. Groenning BA, Raymond I, Hildebrandt PR, Nilsson JC, Baumann M, Pedersen F. Diagnostic and prognostic evaluation of left ventricular systolic heart failure by plasma $\mathrm{N}$-terminal pro-brain natriuretic peptide concentrations in a large sample of the general population. Heart. 2004;90:297-303.

17. Tsutamoto T, Wada A, Maeda K, Hisanaga T, Maeda Y, Fukai D, et al. Attenuation of compensation of endogenous cardiac natriuretic peptide system in chronic heart failure: prognostic role of plasma brain natriuretic peptide concentration in patients with chronic symptomatic left ventricular dysfunction. Circulation. 1997;96:509-16.

18. Januzzi JL, van Kimmenade R, Lainchbury J, Bayes-Genis A, Ordonez-Llanos J, Santalo-Bel M, et al. NT-proBNP testing for diagnosis and short-term prognosis in acute destabilized heart failure: an international pooled analysis of 1256 patients: the International Collaborative of NT-proBNP Study. Eur Heart J. 2005;27:330-7.

19. Choi JH, Cho DK, Song YB, Hahn JY, Choi S, Gwon HC, et al. Preoperative NT-proBNP and CRP predict perioperative major cardiovascular events in non-cardiac surgery. Heart. 2010;96: 56-62.

20. Bibbins-Domingo K, Gupta R, Na B, Wu AH, Schiller NB, Whooley MA. N-terminal fragment of the prohormone brain-type natriuretic peptide (NT-proBNP), cardiovascular events, and mortality in patients with stable coronary heart disease. JAMA. 2007;297:169-76.

21. Berger R, Huelsman M, Strecker K, Bojic A, Moser P, Stanek B, et al. B-type natriuretic peptide predicts sudden death in patients with chronic heart failure. Circulation. 2002;105:2392-7.

22. Gardner RS, Ozalp F, Murday AJ, Robb SD, McDonagh TA. Nterminal pro-brain natriuretic peptide. A new gold standard in predicting mortality in patients with advanced heart failure. Eur Heart J. 2003;24:1735-43.

23. McDonagh TA, Cunningham AD, Morrison CE, McMurray JJ, Ford I, Morton JJ, et al. Left ventricular dysfunction, natriuretic peptides, and mortality in an urban population. Heart. 2001;86: 21-6.

24. Dernellis J, Panaretou M. Assessment of cardiac risk before noncardiac surgery: brain natriuretic peptide in 1590 patients. Heart. 2006;92:1645-50.

25. Feringa HH, Bax JJ, Elhendy A, de Jonge R, Lindemans J, Schouten O, et al. Association of plasma N-terminal pro-B-type natriuretic peptide with postoperative cardiac events in patients undergoing surgery for abdominal aortic aneurysm or leg bypass. Am J Cardiol. 2006;98:111-5.

26. Schouten O, Hoeks SE, Goei D, Bax JJ, Verhagen HJM, Poldermans D. Plasma N-terminal pro-B-type natriuretic peptide as a predictor of perioperative and long-term outcome after vascular surgery. J Vasc Surg. 2009;49:435-42.

27. Waldo SW, Beede J, Isakson S, Villard-Saussine S, Fareh J, Clopton $\mathrm{P}$, et al. Pro-B-type natriuretic peptide levels in acute decompensated heart failure. J Am Coll Cardiol. 2008;51: 1874-82. 
28. Corteville DC, Bibbins-Domingo K, Wu AH, Ali S, Schiller NB, Whooley MA. N-terminal pro-B-type natriuretic peptide as a diagnostic test for ventricular dysfunction in patients with coronary disease: data from the heart and soul study. Arch Intern Med. 2007;167:483-9.

29. Thygesen K, Alpert JS, Jaffe AS, Chaitman BR, Bax JJ, Morrow DA, et al. Fourth universal definition of myocardial infarction (2018). J Am Coll Cardiol. 2018;30:2231-64.

30. Wang J, Tan GJ, Han LN, Bai YY, He M, Liu HB. Novel biomarkers for cardiovascular risk prediction. J Geriatr Cardiol. 2017;14:135-50.

31. Reichlin T, Hochholzer W, Bassetti ST, et al. Early diagnosis of myocardial infarction with sensitive cardiac troponin assays. $\mathrm{N}$ Eng J Med. 2009;361:858-67.
32. Klotz L, Boccon-Gibod L, Shore ND, Andreou C, Persson BE, Cantor P, et al. The efficacy and safety of degarelix: a 12-month, comparative, randomized, open-label, parallel-group phase III study in patients with prostate cancer. BJU Int. 2008;102: 1531-8.

33. Crawford ED, Schally AV, Pinthus JH, Block NL, Rick FG, Garnick MB, et al. The potential role of follicle-stimulating hormone in the cardiovascular, metabolic, skeletal, and cognitive effects associated with androgen deprivation therapy. Urol Oncol. 2017;35:183.

34. Knutsson A, Hsiung S, Celik S, Rattik S, Mattisson IY, Wigren $\mathrm{M}$, et al. Treatment with a GnRH receptor agonist, but not the GnRH receptor antagonist degarelix, induces atherosclerotic plaque instability in ApoE(-/-) mice. Sci Rep. 2016;6:26220. 